\title{
Human Security of Pensionable Officials and Elderly Association Members: The Case of Thailand
}

\author{
Submitted 23/06/20, 1st revision 30/07/20, 2nd revision 25/08/20, accepted 30/09/20 \\ Aimimtham Sukanya ${ }^{1}$, Somnuek Panyasing ${ }^{2}$, Jintana Kampaengsirichai ${ }^{3}$, \\ Eko Priyo Purnomo ${ }^{4 *}$
}

Abstract:

Purpose: This research has three objectives to fulfill, and to make a comparison between the Human Security of Khon Kaen Pensionable Officials and the Elderly Association Members of Thailand with the Human Security at national level.

Design/Methodology/Approach: The samplings are the members of Khon Kaen Pensionable Officials and Elderly Association by a mixed technique, quantitative with questionnaire method and qualitative method by an in-depth interview.

Findings: The findings of Human Security level adjusted from Human Security standard of Social Development and Human Security Bureau, Ministry of Social Development and Human Security commences with higher average score than the national level covering the shelter ownership, education, work and income, society and culture, rights and justice. The lower average of human security than the national level was found in five aspects as well. There are health, family, personal security, social support and political participation.

Practical Implications: In Thailand, particularly in the Northeast, the number of elderly is increasing and it is the largest group of the country. It is thus necessary to prepare the appropriate public services to ensure their quality of life. The research findings are of beneficial to the Social Development and Human Security Ministry to utilize them into practice for sustainable both in physical and mental human security of the elderly. This means the value of efficient elderly will be aware in specific ways by the responsible authorities.

Originality/Value: The significant condition to enhance the wellbeing of mankind is human security both in life and in properties. In the early age, the need for security might not be as high as for elderly persons which are increasing proportionally.

Keywords: Human Security, pensionable officials, elderly, indicators for human security.

JEL Code: E24, J24, K38.

Paper Type: Research study.

\footnotetext{
${ }^{l}$ Chair and Prof. at Department of Public Administration Division \& Social Sciences

Department, Faculty of Humanities and Social Sciences Khon Kaen University

e-mail: sukaim@kku.ac.th;

${ }^{2}$ Public Administration Division \& Social Sciences Department, Faculty of Humanities and

Social Sciences Khon Kaen University

${ }^{3}$ Special Lecturer of General Education Department Khon Kaen University

e-mail: jintana.ka@kkumail.com;

${ }^{4}$ Department of Government Affairs and Administration, Jusuf Kalla School of Government, University Muhammadiyah Yogyakarta (UMY), Indonesia e-mail: eko@umy.ac.id;
} 


\section{Introduction}

The even-changing society has resulted in several changes such as economy, politics, environment and society. These changes are indicators for the human security. These include poverty, losing faith in institutions, job insecurity, economy and other factors affecting their ways of lives. People struggle to have freedom from fear and freedom from want. Aging society has drawn more attentions since older people are increasing in number because of the change of world population structure. The birth rate has declined while people have lived longer, which creates imbalance (Chareonwongsak, 2014). On average, people have lived nine years longer and the number of people, who are aged 60 and over, is over 2,000 million. It is one fifth or 20 percent of the total world population. This trend can be seen in almost every country in Europe especially in Italy, Germany, England and Scandinavian countries as well as in Japan, the country being a full-fledged aging society since 2010 (Chittinandana et al., 2017).

According to the Age Watch Index, Norway ranks top while Afghanistan lasts among 96 countries in terms of the social and economic welfare of people aged over 60 (Sota and Peltzer, 2017). It measures 13 points in four main areas, for example, longevity, pension income, public transportation and poverty rates for persons of 60 ages and over. This information was gathered by non-profit organization Helpage International and United Nations Population Fund. Rating was conducted for the first time in 2013-2014 (ESAUN, 2018). The result showed that Switzerland, Canada and Germany were still among the top-five countries with best social welfares for the older people. The United State of America stood $8^{\text {th }}$ and Japan $9^{\text {th }}$ followed by China (48), Russia (65) and India (69) (ONESDB, 2017).

Based on the population projection of the older people in Southeast Asia in 2050, Thailand is expected to have older people of 10,014,705, which is ranked second behind Singapore and Laos. However, there is not much different among Asean countries. As for the poverty level of the elderly in Thailand, measured using the poverty line by the National Statistic Office of Thailand in 2013 (National Statistical Office 2018), the older the head of the family is, the higher the poverty level would be. The employment rate has gradually declined while people are getting older. Taking all the issues into account, many problems are to be solved and developments must be done for the sake of the elderly.

In less than 10 years, Thailand would become a full-fledged aging society when its population aged 60 and over increases to $20 \%$ of the total population. On March 6, 2015, the Department of Old Persons has been established based on Reorganization of Ministry, Sub-Ministry, and Department Act 2015 (National Statistical Office 2018). Its mission is to support, develop, provide welfares, and protect the rights for the elderly. That can be done by initiating the policy of development, academics, knowledge and innovation. The academic promotion and support, the 
participation in the given areas should also be implemented with the integration of involved parties (Sota and Peltzer, 2017).

According to the population information in the Northeastern Thailand in 2015, there were 266,090 people aged 60 and over in Khon Kaen, which was regarded as the aging society (ESAUN, 2018). Based on the ratio of older people, there were also five districts which were taken as the full- fledged aging society. Moreover, it was among top-five provinces with most older people (Chittinandana et al., 2017). Consequently, it is a main responsibility for Khon Kaen provincial social deployment and human security office to contemplate many aspects of the human security including shelters and inhabits; health, income and employment (Knodel and Chayovan, 2008). With the information, the office, whose mission is to develop the social welfare management system for the people to have life security, would can seek ways to improve the human security for the elderly. That will help promote and support them to enter the aging society effectively.

\section{Literature Review}

The study was conducted using the concepts and theories of Human Security and Aging. The concept of Human Security was taken to study and define security, which was later used as an indicator to determine the criteria for human security.

Based on John and Chayovan (2008), Population Division of the Department of Economic and Social Affairs of the United Nations Secretariat (ESAUN, 2018; Kaewkangwan 1995; Nippanon, Kwasu and Ngang, 2017), the researchers concluded that human security means the way people can lead their lives happily, being free from fear and free from want (Pimdee and Nualnetr, 2017). They should have life insurance that can meet their basic demands and live in the society with integrity. The measurement of the human security was based on the criteria set by the Ministry of Social Development and Human Security and Thammasart university. Ten human securities are: 1) shelters and inhabits 2) health 3) education 4) employment and income 5) family 6) personal 7) social supports 8) society and culture 9) rights and justice 10) politics and participation (Kaewkangwan, 1995; Klungboonkrong, Jaensirisak and Satiennam, 2017; Prawoto, Purnomo and Zahra, 2020; Noja and Cristea, 2018).

For the theory of aging, three theories were used in the study - Biology theory, Psychological theory and Sociological theory. The first one was to explain the relationship between the aging process and chemicals in the body. The persons who have a slower metabolic rate live longer, so do the persons who can reduce protein, fat and carbohydrate (Wajiraphetpranee, 2010).

The second one - psychological theory- stated that the changes of characters and behaviors of the older people were ways to adapt and improve the characters, which have an impact on their overall behaviors (Kantavong, 2018). The last one - 
sociological theory- focuses on aging by considering older persons' ability in maintaining the role and social status. Thanks to the concepts and theories mentioned above, the variables and conceptual framework can be summarized as follow:
1) Shelters and inhabits
6) Personal
2) Health
7) Social support
3) Education
8) Society and Culture
4) Employment and Income
9) Rights and Justice
5) Family
10) Politics and Participation

Human Security Management for the elderly in Khon Kaen

\section{Data Collection}

The sample group are members of Khon Kaen Pensionable Officials and Elderly Association, Thailand and these people must be 60 and over. Out of the group, 60 people were chosen as the sample size based on accidental sampling. They were the ones participating at the activities hosted by association in August and willing to give information and answer questionnaires (Chareonwongsak, 2014). The chosen group were also in line with the objectives of the study (Purnomo, Anand and Choi, 2018). For the quantitative study, questionnaires featuring 60 items were distributed and all of them were returned to the researchers (Wangkiri, 2009).

Descriptive statistics deployed to explain data were frequency, mean and percentage. As for the qualitative one, it was conducted using a structured in-depth interview (Bryman and Burgess, 2016). The target group of five people, who were willing to join an interview, were picked according to purposive sampling. The interviews were recorded by recorders. They were then coded and analyzed. The qualitative data were explained using a descriptive while the quantitative one using a table and a descriptive (Denzin and Lincoln, 2011).

\section{Data Analysis}

The data analysis showed that the mean scores of the association members were higher than overall mean scores of the country in five areas - home ownership, education, employment and income, society and culture, and rights and justice (Purnomo, Ramdani, Salsabila and Choi, 2020). The association members had a mean score of 6.7, compared to 4.51 in the country in home ownership (National Statistical Office, 2018). They have a mean score of 5.03 in education while the country got 3.64. For employment and income, they got a mean score of 7.12 with the country making 3.03. In terms of society and culture, the association member got a mean score of 2.25 , compared to 2.21 of the country. They manage to get a 
mean score of 6.00 in the area of right and justice while the country had 5.94 (ONESDB, 2017).

There were five areas the association members scored lower than overall the overall mean scores of the country. It featured health, family, personal, social support and politics and participation (Intarasaksit and Pitaksanurat, 2019). Their mean score in health was only 9.9 with the country's overall score was 10.22. They got a mean score of 6.52 , compared to 6.83 in the country in terms of family. For a personal area, the association members earned 6.08 with the country getting 6.27. Taking social supports into consideration, they received a mean score of 2.43 and the country took 2.94. In terms of politics and participations, they had a mean score of 3.13, well below the country which gets 3.52 .

Overall, a mean score in association members' security was also below that of the country as a whole. They had a mean score of 4.64, compared to overall mean score of 4.91 in the country as shown in Table 1.

Table 1. Mean scores of Members of Pensioners and Elders Association, Khon Kaen and the overall mean score of the country

\begin{tabular}{lll}
\hline Human Security & $\begin{array}{l}\text { Association } \\
\text { member's } \\
\text { mean scores }\end{array}$ & $\begin{array}{l}\text { Overall mean } \\
\text { scores in } \\
\text { country }\end{array}$ \\
\hline 1. Shelter and inhabits & & \\
$\quad$ Shelter and inhabits ownership & 6.7 & 4.51 \\
2. Health & 9.9 & 10.22 \\
$\quad$ Received medical treatment in 2016 & 2.97 & 3.75 \\
$\quad$ Under health scheme & 1.03 & 1.01 \\
$\quad$ Exercise & 3.10 & 2.15 \\
$\quad$ Healthy Food Awareness & 2.80 & 3.31 \\
3. Education & & \\
$\quad$ Highest Education & 5.03 & 3.64 \\
4. Employment and Income & 7.12 & 3.03 \\
$\quad$ Monthly income & 5.45 & 1.61 \\
$\quad$ Incurring income & 1.67 & 1.42 \\
5. Family & 6.52 & 6.83 \\
$\quad$ Family harmony & 3.13 & 3.42 \\
$\quad$ Participate in family business & 3.38 & 3.41 \\
6. Personal & 6.08 & 6.27 \\
$\quad$ Life safety & 3.03 & 3.15 \\
$\quad$ Property safety & 3.05 & 3.12 \\
7. Social Supports & 2.43 & 2.94 \\
$\quad$ Insurance & 1.35 & 0.88 \\
Emergency contact when you are in trouble & 1.08 & 2.06 \\
8. Society and Culture & & \\
Participate in social and cultural activities & in & 2.25 \\
$\quad$ community & 6.00 & 5.94 \\
9. Rights and Justice & &
\end{tabular}


Legal proceedings with juristic persons 3.00 2.96

Legal proceedings with /Getting unfair treatment from government agencies

3.00

2.98

10. Politics and Participation

Voting and voicing their political comments

3.13

3.52

total

4.64

4.91

Source: Own.

\subsection{Qualitative Data Gained from in-Depth Interviews with Association Members}

\section{a) Shelters and Inhabits}

Association members found it important to have their own house and it is the best for them because they feel secure and safe to have their own house. To live in other people's house, whether it is their children's house or relatives' houses, they feel burdened, depending on the others (Kantavong, 2018). However, they would feel uncomfortable if they have someone else to stay in their own house. It is all about privacy and convenience for both sides. "After retirement, a house is necessary for me and other older people. Having our own houses means security and safety." (Interview, August 2017). "It is an important issue. If we do not have our own houses, it would have a problem. To live with our children or other people means we are going to burden them with our problem. I do not know if they are going to take care of me" (Interview, August 2017).

\section{b) Health}

Association members all agree that being healthy is essential for the elderly. If they stay healthy, they could save medical expenses. They should try to be healthy by doing regular exercises specially designed for the older persons such as walking, jogging, golf or petanque. They must do by themselves. Moreover, an annual medical check-up and healthy food consumption are also required. "If we stay healthy or without illness, we do not have to pay for medical expenses. We need to be health concerned and exercise every day" (Interview, 10 August 2017). "It is really important. Getting old, we must play sports suitable for the older people. Playing golf with friends, jogging or playing petanque. No one can exercise for us. Being healthy cannot be bought, you need to do it by yourself" (Interview, 10 August 2017).

\section{c) Education}

From the interview, association members all agreed that working as a civil official is about dignity and job security. They could work for the government as planned until retirement because they have good education background. It is different from their ancestors who lacked educational opportunities. "I have been educated so I am able to work for the government and make a living. It is different from the past when the older people including my parents did not have high educations. They just make ends meet. In our generation, we had a chance to study and work for the government 
side. With a salary, we can improve our standard of living" (Interview, 10 August 2017).

\section{d) Employment and Income}

From the interview, they are happy with their income and savings because they have incurring income of pension although it has decreased after retirement. Money management is well planned and there is no much burden expenses to cover. They are in debt but it is not much to worry about. "After retirement, my income has decreased. So, I need to be better in managing my income and expense. I also have my saving and a house for rent while my husband has an income security. We do not any debt. After retirement, I get good welfares from the office I worked for. As a family, we also have carefully planned on how to spend money, which is an insurance for us and our family business. The country's economy might be in crisis in the future. I decided to get a monthly retirement pension instead of retirement bonus because I am paid continuously. If I took a retirement bonus, I would get a lump sum payment. However, I do not have a financial problem. I do not need that" (Interview, 10 August 2017).

\section{e) Family}

Association members said that they had life security because there was harmony in their families. Their children have still looked after them even that they have their own families. Meanwhile, they occasionally helped their children when needed. "I have been living happily. After retirement, I have helped my children to run his shop. I try to help them as best as I could. If they are happy, I would definitely be happy" (Interview, August 2017). "I feel secure in my life. My children take care of me. They are married but they still look after me. I just spend my life, also taking care of my children and nieces. There is nothing to worry" (Interview, August 2017).

\section{f) Personal}

According to the interview, association members found that life and property safety seems to be lower since more social and economic problems have risen. They feel concerned about next generations. "People are more competitive and depressed. They compete against each other to make a living. There is a lack of generosity especially in the city. While social problems including child and family problems are increasing, the social safety has decreased. The social problem and morality crisis are often seen even in organizations such as a religion section. I am really concerned about next generation if these social and economic problems have not been fixed" (Interview, August 2017).

\section{g) Social supports}

From the interview, they feel secure about social supports because they have got a monthly retirement pension. When they are in trouble, they can ask for help from such people as their relatives and children. "I receive a retirement pension every month. It is enough because I do not have any debt" (Interview, August 2017). 
"I think that I have security in my life. I got recognition and respect from society and I am also looked after by my children. I have my own retirement pension and I am healthy. I just want to spend my life like this" (Interview, August 2017). "I feel happy to stay home. I am here alone but my children always visit me and stay here for a few days. They take care of me really well" (Interview, August 2017).

\section{h) Society-Culture}

From the interview, association members agreed that society and culture are part of their lives. Through these two things, they can meet and talk to each other, easing their loneliness. The older people are willing to join social and cultural activities. They do not want to be just a participant. Instead, they want to show how important they are for the society. When being given a chance, they are not reluctant to join the activities specially and properly designed from the older people. "Society and culture are parts of our lives where we meet friends. We chat, discuss and share the ideas. With that, we are not lonely. We join religious activities in temples, weddings or funerals" (Interview, August 2017). "In fact, society play a key role not only for the elderly but for all the generations. It depends on which group of people you are going to focus. The benefits the society would get will decide who they are going to focus. If they think they can benefit from the elderly, they would turn to the elderly" (Interview, August 2017).

\section{i) Rights and Justice}

The data analysis showed that members of Khon Kaen Pensionable Officials and Elderly Association are secure in terms of rights and justice with the mean score of 6.00. No one is on legal proceedings of copy right and fraud with juristic persons (Luenam et al., 2018). Moreover, there is no one involved in legal proceedings of copy right or of getting unfair treatment from government agencies. It is 100 percent (60 persons).

\section{j) Politics and Participation}

From the interview, association members have given importance to politics and political participations because they are civil officials and feel it is the duty for the Thais to perform and exercise their rights (Techataweewan et al., 2018). That includes elections and other political activities. "I exercise my right at all the levels of elections. I also want to set an example for others. I am a civil official. I always asked my neighbors to vote in the elections" (Interview, August 2017). "I vote in every election. I never miss the election. When they give me a chance to vote, I must go. If I stay quiet, the country would be the same. The country will not make any progress in development. We need to express our comment or opinion if we want them to do something. If we do not go, we cannot blame or comment them later. So, if we do not take a chance they give, we would not be able to blame them" (Interview, August 2017). 


\section{Study Results, Summary, and Contribution}

The analysis of quantitative data found that the area of society, culture, and tradition refers to the participation in various social activities such as making merit on a New Year celebration, a temple fair and a variety of events (Kantavong, 2018; Techataweewan et al., 2018; Thanatasetha-Angkul, 2003; Isaan, 2018). The study showed that the mean score of the elderly participating in social activities was lower than the overall mean score of the country. According to the United Nations (UN) (2018), Wangkiri (2009), and the World Health Organization, the old people are the ones who live in the last stage of their lives (Guler et al., 2018). It is the deteriorating age in terms of physicality, mentality, and social work. However, the level of deterioration would be different. In addition to the above-mentioned symptoms, the chronological age of 60 years is an international criterion to identify 'elderly or older persons'. Therefore, the criteria of participation in social activities may be adapted due to the physical and mental deterioration.

It is in accordance with Sangsri $(2005 ; 2017)$ who studied the improvement of the older persons' the quality of life in Thai society in terms of social and recreational activities and sought their opinions and those of people close to them about the ways to provide appropriate services of social and recreational activities for the elderly. The results showed that ninety percent of the elderly occasionally participated in social activities in the community such as religious ceremony, traditions, festivals, neighbors' activities while eleven percent of them joined religious groups (Klungboonkrong, Jaensirisak and Satiennam, 2017). Twenty-three percent were members of the elderly club and forty-three percent were not members of any clubs or groups. The researcher said that even that the mean score in this area was lower than that of the country, taking each item in the questionnaires into account, it was found that most of the elderly participated in social activities quite often and some of them had no participation in any social activity. It is interesting to find the way to continue supporting the former group and encourage the latter one to join social activities (Sota and Peltzer, 2017). The important thing was to give social welfares the elderly need or host any group event for them to join and work. According to the study, the main reasons they could not participate in social activities were that they found it inconvenient and they could not afford it (Keeratikasikorn, 2018). Therefore, the welfare or allowances must be taken into account when the elderly will be asked to take part in social activities.

Education: most association members completed their bachelor's degree or higher and with that, they can contribute in transferring knowledge and giving some advices to others (Kantavong, 2018). The government might provide further education guidance for the elderly who are interested in studying at a higher level.

Employment and income: these are related to the one who is knowledgeable and capable in his own career and the one who spend money wisely and make a saving. There is no debt problem. According to the study, most of the elderly gained income 
from work and monthly savings at a low level. It is consistent with the study of Jiwapattanakun, Adisornprasert, and Yannasomboon (2011), which examined factors affecting the saving and spending behavior of the elderly. The results showed that the major source of income was from their children. An average personal income per month was less than or equal to 5,000 baht, which is considered low incomes (Jiwpattanakun, Adisornprasert and Yanasomboon, 2011). From the social context of the sample group, the elderly received low incomes and lacked work opportunities. They should be given more opportunities to work. In other countries, there are job opportunities for the elderly such as volunteer jobs that have been done by the elderly for a long time. However, the volunteer work must be suitable for the elderly based on their ability (Wajiraphetpranee, 2010). The job features the likes of elevator services and moping the floor, which does not require a lot of force. With such jobs, they can earn more money, which can be saved for the future.

Personal security: safety in life and property. It was found that the elderly felt insecure in their lives and properties at a low level. However, the researchers realized that some sample groups still needed assistances. The feeling of insecurity in lives and properties might happen because they do not have enough money to spend on protecting their lives and properties (Keeratikasikorn, 2018). They have a limited income and must focus on making ends meet. Imbalanced expenses and incomes could affect personal security.

Social support means having social security guarantees such as social security, provident fund, cremation welfare, or insurance including the supports from people who can rely on. The study revealed that most of the elderly received social security at a low level when compared to the overall mean score of the country (Chittinandana et al., 2017). When considering the results from the questionnaires in detail, the elderly still had social security in the forms of cremation welfare, life insurance, social security, provident fund, retirement bonus and monthly retirement pensions respectively. Apart from their family members, they could ask for help from friends and neighbors when they are in trouble. These members still had social security and supports. However, there were a few respondents unable to find a supporter. These issues needed help for progressive development and a higher mean score. All relevant organizations should realize the importance in giving supports for the elderly and helping them to lead their lives as good as possible. Therefore, the interesting issue was the proposal to establish a service center that can provide advice and support for the older persons quickly and effectively.

Family is concerned with people's ability to perform their duties appropriately. There were activities to strengthen a family harmony. According to the study, the mean score of the family was at a low level when compared to that of the country. However, when considering in depth, it was found that most of the elderly were likely to have reconciliation in their family and help lessening family burdens. It is consistent with the study of Chittinandana (2017). She investigated the role of the elderly who lived happily with family in a semi-urban community, Nakhon 
Ratchasima province to explain the context and family characteristics of the elderly in a semi-urban community including the definition of "elderly" and "wellbeing" of the elderly as well as their roles, families and communities for the well-being (Wajiraphetpranee, 2010). The results showed that the elderly were still able to perform their daily tasks and lived happily with the family. They could take care of themselves in terms of physicality, mentality, and spirituality (Intarasaksit and Pitaksanurat, 2019). They cultivated their grandchildren and play a key role in community. Family is considered essential for everyone especially the elderly who require a special care. Creating the esteem for the elderly and their families should begin with asking about living and having a home party. This is considered to create reconciliation and being a part of the family, which gives them more self-esteem, being a part of the family and communities. In the case that the elderly do not have reconciliation or family participation, the government needs to assign community leaders to survey and find a way to provide initial supports and make mutual understanding if possible (Purnomo et al., 2019).

Health refers to a good condition of physicality and mentality. There is no serious illness or chronic disease. They are equipped with basic knowledge in health care and have always practiced in promoting their health. The results showed that the majority of the elderly had health security at a high level. However, it is not consistent with the study of Thanasetha-Angkul et al. (2003) who investigated the health promotion behaviors of the female elderly in Muang district, Khon Kaen province, and the needs of the elderly suffering from illness and stepping closer to the elderly condition (Intarasaksit and Pitaksanurat, 2019). The result showed that the overall health care of the female elderly was at a low level. The majority of the elderly have all three full meals that were well-cooked. They drank less water. Only a small number of elderly exercised regularly. Some of them suffered from urinary incontinence, insomnia, stress caused by family conflicts including an economic problem (Luenam et al., 2018). Most of them had no annual medical check-up. They tended to buy medicine by themselves when they suffered from a minor illness. And if the symptoms are getting worse, they would go to see a doctor at hospitals.

Based on the study of Human Security for members of Khon Kaen Pensionable Officials and Elderly Association, Thailand, the guidelines for the development of (1) health (2) family (3) personal (4) social support (5) politics and participation should be as follows:

Health: there should be a campaign for the elderly to have an annual medical checkup. The government and related organizations should closely work with hospitals to set up specific treatment zones for large numbers of the elderly. They can also provide a clinic for the elderly in hospitals where most of the association's members always receive the service so that they can have immediate supports. Scholarships should be allocated to produce more qualified doctors for the older patients who are increasing in number. 
Family: relationship in the family should be strengthened allowing the elderly to participate in various activities such as taking care of children, having meals together at home, and sharing opinions, love, and warmth for the elderly. Because of that, the elderly are going to have more self-esteem. The elderly who have time and ability to teach should be encouraged and supported to take a part in teaching their descendants at home to create unity and harmony. The descendants themselves would realize the importance and value of the elderly in their own family.

Personal security: the elderly should be closely treated with care and warmth, whether walking ups and downs at different level areas, especially at high areas. They should also be closely watched when they take a shower or use a toilet. Necessary environments, welfares and facilities in everyday life should be provided. It includes living rooms, bedrooms and dining room, adjustable bed, wheelchair, potty, toilet, and sanitary pads. A trustworthy caregiver should be taken to oversee the older persons' properties, which must be kept in an entirely enclosed place. Valuable items should not be worn in public places to avoid loss or extortion,

Social support: there should be a club or an association of the elderly, who are knowledgeable and capable. Apart from a chance to do charity work, the elderly should have job opportunities and get encouraged to join social activities, for example; traditional fairs and annual festivals.

Politics and political participation: the elderly should have opportunities to express their opinions at a public forum on a political issue. A particular area or channel should be provided to facilitate them when they go to vote in the election.

The organizations responsible for human security or related parties must be aware of the importance of the development of the elderly and make it secure. They should realize the values of the elderly and make a good use of those values to make a great contribution for the country instead of being burdened (Intarasaksit and Pitaksanurat, 2019; Wajiraphetpranee, 2010). If they can do that, this will help develop the country sustainably and steadily.

\section{Conclusions}

Human security is what everyone needs. People are getting older and the more their physical condition deteriorates, the greater the need for security in life and property would be. The knowledgeable and capable elderly, who are still active, should be encouraged and supported to work for others. They can work as volunteers to teach and pass on knowledge to others based on their skills. For health, there should be a campaign for the annual medical check-up and closer cooperation with the hospital or related organization in accommodating the treatment zone for the elderly including setting up clinics for the elderly in each sub-district or district.It is essential to encourage the elderly to participate in social activities, strengthen relationships within the family to create mental stability for the elderly. They should 
be closely treated when they take a shower or use a toilet. Necessary environments, welfares and facilities in everyday life should be provided. It includes living rooms, bedrooms and dining room, adjustable bed, wheelchair, potty, toilet, and sanitary pads. There should be a trustworthy caregiver responsible for property protection of the elderly. Valuable items should be kept in an entirely enclosed place. They should not be worn in public places because of the risk of loss or extortion. The elderly should be closely treated with care when they walk on areas of different levels, especially at high areas. All the issues should be done to make sure that the elderly can have life and property safety and get ready to enter the aging society confidently. Instead of being burdensome for the family and the country, they can become the efficient elderly who are capable of make great contributions to develop the country in the future.

\section{References:}

Bryman, A., Burgess, G.R. 2016. Analyzing Qualitative Data. London and NY: Routledge. Chareonwongsak, K. 2014. World Society, Elderly Society. In 1st Edition, Bangkok: The Office of the National Buddhism Office.

Chittinandana, Dhanaporn, Nakanang Kulnartsiri, Jaree Pinthong, Paphatsorn Sawaengsuksant. 2017. Aging Population: Global Perspectives.

Denzin, Norman K., Yvonna S. Lincoln. 2011. The SAGE Handbook of Qualitative Research. Thousand Oaks, CA Sage.

ESAUN. 2018. World Population Prospects. http://esa.in.org/undp/wpp/index.htm.

Guler, Jessy et al. 2018. Global Collaborative Team Performance for the Revision of the International Classification of Diseases: A Case Study of the World Health Organization Field Studies Coordination Group. International Journal of Clinical and Health Psychology.

Intarasaksit, Prat, Somsak Pitaksanurat. 2019. Factors Influencing Appropriate Management of Household Hazardous Waste in Nakhon Nayok, Thailand: A Multilevel Analysis. Journal of the Air \& Waste Management Association 69(3), 313-319.

Jiwpattanakun, A.W., Adisornprasert, Yanasomboon, S. 2011. Factors Affecting Saving and Spending Behavior of the Elderly. Strategy Innovation Building.

Kaewkangwan, S. 1995. Psychology of Life Development at All Ages. In 6th Edition, Bangkok: Thammasat University Press.

Kantavong, Pennee. 2018. Understanding Inclusive Education Practices in Schools under Local Government Jurisdiction: A Study of Khon Kaen Municipality in Thailand. International Journal of Inclusive Education, 22(7), 767-786.

Keeratikasikorn, Chaiyapon. 2018. A Comparative Study on Four Major Cities in Northeastern Thailand Using Urban Land Density Function. Geo-spatial Information Science 21(2), 93-101. https://doi.org/10.1080/10095020.2018.1455320.

Klungboonkrong, Pongrid, Sittha Jaensirisak, Thaned Satiennam. 2017. Potential Performance of Urban Land Use and Transport Strategies in Reducing Greenhouse Gas Emissions: Khon Kaen Case Study, Thailand. International Journal of Sustainable Transportation 11(1), 36-48. https://doi.org/10.1080/15568318.2015.1106249.

Knodel, John, Napaporn Chayovan. 2008. Population Aging and the Well-Being of Older Persons in Thailand: Past Trends, Current Situation and Future Challenges Papers in Population Ageing. Bangkok.

Luenam, Amornrat et al. 2018. Socioeconomic Disparities and Chronic Respiratory Diseases 
in Thailand: The National Socioeconomics Survey. Informatics for Health and Social Care, 43(4), 348-361. https://doi.org/10.1080/17538157.2017.1363760.

National Statistical Office. 2018. Results of the 2014 Elderly Population Survey. http://www.nso.go.th/.

Nippanon, Parisa, Niyon Kwasu, Tang Keow Ngang. 2017. Healthy Exercise of Registered Female Nurses in Khon Kaen Province, Thailand. Procedia - Social and Behavioral Sciences, 237, 137-143.

http://www.sciencedirect.com/science/article/pii/S187704281730054X.

Noja, G.G., Cristea, M. 2018. Working Conditions and Flexicurity Measures as Key Drivers of Economic Growth: Empirical Evidence for Europe 1. Ekonomicky Casopis 66(7), 719-749.

ONESDB. 2017. The Definition of Well-Being and Security in the Lives of Thai People. Office of the National Economic and Social Development Board. http://www.nesdb.go.th (October 17, 2016).

Pimdee, Atipong, Nomjit Nualnetr. 2017. Applying the International Classification of Functioning, Disability and Health to Guide Home Health Care Services Planning and Delivery in Thailand. Home Health Care Services Quarterly, 36(2), 81-95. https://doi.org/10.1080/01621424.2017.1326332.

Prawoto, N., Purnomo, E.P., Zahra, A.A. 2020. The Impacts of Covid-19 Pandemic on Socio-Economic Mobility in Indonesia. International Journal of Economics and Business Administration, 8(3), 57-71. doi: 10.35808/ijeba/486.

Purnomo, E.P., Anand, P.B., Choi, J.W. 2018. The complexity and consequences of the policy implementation dealing with sustainable ideas. Journal of Sustainable Forestry, 37(3), 270-285. doi: 10.1080/10549811.2017.1406373.

Purnomo, Eko Priyo et al. 2019. Land Ownership Transformation before and after Forest Fires in Indonesian Palm Oil Plantation Areas. Journal of Land Use Science, 1-15.

Purnomo, E.P., Ramdani, R., Salsabila, L., Choi, J.W. 2020. Challenges of community-based forest management with local institutional differences between South Korea and Indonesia. Development in Practice, 1-12. doi: 10.1080/09614524.2020.1749561.

Sangsri, S. 2005. Learning Management of Lifelong Learning Resources. Bangkok.

Sota Chulaporn, Karl Peltzer. 2017. The Effectiveness of Research Based Learning among Master Degree Student for Health Promotion and Preventable Disease. Faculty of Public Health, Khon Kaen University, Thailand. Procedia - Social and Behavioral Sciences, 237, 1359-1365. http://www.sciencedirect.com/science/article/pii/S1877042817302264.

Techataweewan, N. et al. 2018. Human Body Donation in Thailand: Donors at Khon Kaen University. Annals of Anatomy - Anatomischer Anzeiger, 216, 142-151. http://www.sciencedirect.com/science/article/pii/S0940960217301504.

Thanatasetha-Angkul, S. 2003. The Study of Health Behavior of People in Rural Communities in Mueang District, Khon Kaen Province. Khon Kaen.

TheIsaanRecord. 2018. The Parable of the Poisoned Arrow: Thailand 4.0 Edition. https://isaanrecord.com/2018/06/09/the-parable-of-the-poisoned-arrow-thailand-4-0.

Wajiraphetpranee, S. 2010. The Role of the Elderly Living Happily with Family in a SemiUrban Community, Nakhon Ratchasima Province.Journal of Health and Nursing, 16(1), 50-59.

Wangkiri, S. 2009. The Role of Caring for the Elderly in Phitsanulok Municipality. Pibulsongkram Rajabhat University. 